\title{
Economic geographies of power: methodological challenges and interdisciplinary analytical possibilities
}

\section{Please cite as:}

Faulconbridge JR (2012) Economic geographies of power: methodological challenges and interdisciplinary analytical possibilities. Progress in Human Geography 36 (6) 734-756

\section{Introduction}

For economic geographers, key to explaining the uneven spatial structure of the economy and its trajectories of change over time is analysis of power - ie, analysis of the way actors marshal and exercise resources as part of attempts to shape the behaviour of others and in the process gain economic advantage. For example, power relations are said, amongst other things: to determine whether the activities of transnational corporations (TNCS) in developing countries lead to industrial upgrading or a 'race to the bottom' (Coe et al., 2004; Tokatli, 2007; Yeung, 2009); to be responsible for the reproduction of economic inequalities at the national (Brenner, 1998; Massey, 2007) and international scale (Swyngedouw, 1997); to be the cause of the spatially uneven diffusion of both business practices (Clark et al., 2002; Jones, 2008; Wrigley et al., 2005) and neoliberal models of economic governance (Larner and Walters, 
2000; Kelly, 2001); and to shape labour relations and the success of unions and other bodies in defending workers rights and fighting capitalist exploitation (Christopherson, 2007; Cumbers et al., 2008; Routledge, 2003). It is, therefore, unsurprising that the development of a conceptual and methodological framework for economic geographical analyses of power continues to be a core part of research agendas (Allen, 2003, 2004; Faulconbridge and Hall, 2009; Herod and Wright, 2002; Massey, 1999). In particular, calls have been made for the development of empirical approaches that provide not only meso-scale description of who in an economic relationship has power and the impacts of their powerfulness, but also micro-scale analysis of how actors become powerful in time-place specific ways (Jones, 2008; Sharp et al., 2000; Sunley, 2009; Tokatli, 2007; Weller, 2009; Yeung, 2005). This involves scrutinising what Allen (2003) calls the 'modalities of power' - the different forms of power deliberately constructed by actors - and the 'whereabouts' of power - the way geography shapes the assets available to construct power, the nature of interactions between contending parties, and ultimately the power relations produced.

In this paper I consider how the kinds of rich empirical analyses needed to enhance understanding of the modalities and whereabouts of power can be better developed. As Sayer $(2004,268)$ points out, "spatial theory can make only vague allusions to particular kinds of spatio-temporal organization...[and] only more concrete analyses can hope to say more"; yet economic geographers, by their own acknowledgement (Yeung, 2005; Sunley, 2009; Tokatli 
2007), still have some way to go in order to get to grips with the methodological and analytical challenges of developing temporally and spatially nuanced empirical studies of power. To develop more concrete analyses I suggest, in particular, that 'new' economic geographers (Yeung, 2003) need to revaluate and refine their methodological and analytical toolkits to overcome problems with the validity of the data collected and with the reflexivity of analyses generated. Together these shortcomings mean that too often, and unnecessarily in the context of the toolkit available to 'new' economic geographers, the socio-spatial processes involved in constructing power relations are studied obliquely, superficially and in ways that have limited explanatory capability. I suggest that for more nuanced analyses to be developed economic geographers need not abandon existing approaches to empirically studying power, but must recognise that: certain research methods that already exist within economic geographers' toolkits need to be deployed in more precise ways - eg, close dialogue; certain methods need more widespread use - observation informed ethnography in particular; and that existing analytical tools - critical discourse approaches in particular - need refining to allow data to be both more reflexively analysed and triangulated. I show that such methodological advances are possible if economic geographers take seriously what can be learned from approaches to empirically analysing power elsewhere in the social sciences - in management and linguistics in particular - and that an evolutions rather than revolutions in approaches to empirical research are needed. 
The rest of the paper develops these ideas as follows. In the next section I outline in more detail existing geographical conceptualisations of power. This reveals a number of core questions about power which need to be addressed through an appropriate empirical research design. It also reveals a number of the limitations of existing empirical studies of power. Section three then exemplifies how gazes outside of economic geography can help refine analyses of power so as to overcome existing methodological limitations. It does this, firstly, by considering how gazes towards the work of critical management scholars on identity regulation provide insights into the kinds of methods needed to collect valid data and, secondly, by considering how gazes towards work in linguistics on critical discourse analysis provide insights that can help enhance analytical reflexivity in studies. The concluding section considers the implications of the paper for future work on power and for economic geographical debates about research methods and practice more generally.

\section{Economic geographical conceptualisations of power}

A diverse array of social science theories of power - from the work of Arendt (1958) through Mann (1986, 1993), Parsons (1963), Weber (1978), Giddens (1977), Foucault (1980) and Deleuze and Guattari (1988) - have informed geographical interpretation of 'what power is and does' (Clegg, 1989). In drawing on this work, economic geographers have concentrated less on reconciling differences between the perspectives and more on use of the various perspectives to develop a theoretical framing of the various ways spatiality and temporality 
affect power relations. The work of John Allen $(2003,2004)$ has been highly influential in this regard and is complemented by a wider body of analysis targeting specific empirical questions about the time-place specificities of power, its effects and reach (see for example Bathelt and Glücker, 2005; Cumbers et al., 2008; Faulconbridge et al., 2009; Johns, 2006; Jones and Search, 2009; Routledge, 2003; Sharp et al., 2000; Tokatli, 2007; Weller, 2009; Yeung, 2005).

Combined, this work identifies three core foci of economic geographical analyses: (1) asset availability; (2) the practice of exercising assets and; (3) responses to the exercising of assets by contending parties.

In terms of assets, the focus for analytical scrutiny is on how, at different moments in time or in different places, the ability of individuals or groups to become powerful and the impacts of their power are determined by variations in asset availability. Assets can be structural - eg, existing uneven wealth distribution, regulation, access to know-how, hierarchically defined power over others in an organization - and/or formed through social agency - eg, scalar discourses or particular world views that are deliberately constructed to empower some groups and disempower others. Illustrating the importance of geographical variations in asset availability, Liu and Dicken (2006) reveal that the difficulties Toyota faced in penetrating the Chinese market were due to the company's late entry into the country in 1998, a time when many of the assets that the firm's competitors had used to become powerful no-longer existed. For example, Volkswagen's success when entering China in 1985 was a result of 
regulators desires to leverage the expertise of the company (one of its key assets) to upgrade indigenous suppliers, leading to favourable conditions for investment. By 1998 such expertise was no-longer needed and, therefore, Toyota did not have access to the key asset that had previously been used by car companies to negotiate acceptable terms of entry into China's markets. Christopherson (2007) reaches similar conclusions about the importance of asset availability, but in her case in relation to the spatial specificity of assets. Christopherson reveals that Wal-Mart's failure to forcibly reconfigure retail markets in Germany yet success in other countries was a result of the unavailability to the firm in Germany of key assets deployed in other countries; assets including being the main customer in supply chains, regulation that allows compulsory changes to workers practices and bans on unions, and the existence of a sympathetic and supportive government.

The second component of geographical analyses of power relations is a simultaneous focus on the exercising of available assets. Assets such as financial resource or regulation are not themselves forms of power. What matters is the way available assets are used to develop "assorted attempts at the calculated administration of diverse aspects of conduct through countless, often competing, local tactics of education, persuasion, inducement, management, incitement, motivation and encouragement" (Rose and Miller, 1992, 175). Exercising strategies have a significant impact on power relations because, at one level, they create time-space heterogeneity in the impacts of powerful economic actors. As Table 1 reveals, an asset such as 
regulation may be marshalled to construct one of several different modalities of power, with each modality having a different effect because of underlying differences in how compliance is gained and behaviours shaped. Consequently, a decision, for example, by the World Trade Organisation to dominate a government in one place will lead to assets being used in different ways and with different outcomes compared with a decision to coerce a government in another place (see Table 1, and for an empirical example of the diverse outcomes resulting from such differences in exercising strategies see Halliday and Caruthers, 2009). Studying the contingent influences on the exercising of resources and the resultant production of one modality of power or another is thus vital to explore powers spatio-temporal specificities.

[Insert Table 1 somewhere here]

At another level, it is also important to understand exercising strategies because variations in the mediating devices used to exercise power determines the reach of relations. All modalities can, in theory, be constructed through assets exercised at a distance (using mediating devices as diverse as emails, memos, reports, consultations and tender documents, and virtual interactions by telephone or video-conference) or in proximity (using informal or formal faceto-face encounters). However, in reality because of the work that has to be achieved to change behaviours (see Table 1), the choice of mediating device will vary according to time/place specificities in the relationships between contending parties, something which in turn shapes the role of different local and/or global actors in the exercising of control over economies, 
individuals and groups. Jones and Search (2009), through a case study of the UK private equity industry and power relations between investors and firms invested in, illustrate clearly the importance of analysing these intertwined relationships between exercising strategies, modalities and reach. They reveal, first, that private equity groups move from manipulating those they seek to control during the acquisition stage to domination in the post-acquisition stage. This change in the nature of power relations leads to variations at different stages of the acquisition process in the impacts of private equity firms on the business practices of those they acquire (from tentative and contestable, to resignation and compliance), thus highlighting how exercising strategies and outcomes are always temporally specific. Jones and Search also reveal, second, that the role of face-to-face contact in pre- and post-acquisition stages varies depending both on the work that needs to be done to change the behaviours of contending parties, and on the socio-cultural characteristics of the relationships that exist between contending parties. Face-to-face contact becomes more likely as levels of trust, mutual understanding and shared culture decline. This reveals how geographies of power (of private equity firms) are topological, being determined by the existence (or not) of social space in which trust, mutual understanding and shared culture exist.

The third component of economic geographical analyses of power involves considering the unpredictable ways that exercising strategies are responded to by contending parties. Considering the reactions of contending parties is valuable because there is no teleological 
connection between strategies adopted to exercise assets and outcomes in terms of power relations and their effects. As Weller $(2009,797)$ argues using the case study of the Australian airline industry, "The result [of the construction of power relations] can be understood only by taking into account the trajectories of these relationships and considering how actions produced a variety of anticipated and unanticipated second- and third-order repercussions". Specifically, in Weller's case study several airlines in the same societal and territorial space of Australia are shown to be affected differently by the strategies of regulators and the government because of variations in their response to privatisation and re-regulation, responses that were determined by the assets available to the airlines as they jockeyed for position in the new market. This ultimately led to the demise of one airline - Ansett - that was unable to effectively respond to changes being demanded and the survival of another Qantas. The significance of Weller's finding relates to what is revealed about the cause and impacts of time-place specific responses to exercising by contending parties. Depending on the assets available to those having power wielded over them, reactions to exercising, the appropriateness of using different mediating devices, and in turn the modality of power constructed and the impacts of that power will vary.

Sayer $(2004,262)$ refers to the approach outlined above, which involves studying both those seeking to become powerful (components (1) and (2) above) and those who have power exerted over them (component (3) above), as the 'double contingency' of analyses of power; 
recognition of this contingency being crucial if power is to be conceived of as a relational social construction. As noted in the Introduction to this paper, Sayer also identifies as a pressing research agenda empirical research of this social contingency so as to further concretise understanding of the geographies of power. But this raises the question of how double contingencies might be empirically studied using the existing tools of economic geographical research?

Power: methodological and analytical challenges

The foundations for effective empirical analyses of the geographies of power are undoubtedly present in existing literatures. Drawing on the principles of the 'new' economic geography research paradigm (see Amin and Thrift, 2000; Thrift and Olds, 1996), a paradigm that takes the cultural and social foundations of the economy seriously by conceptualising all economic activity as embedded in a socio-spatial world that is complex, contingent and impossible to represent in stylized facts (Clark, 1998; Yeung, 2003), detailed and often comparative case studies of power relations have been developed through in situ research. The methods used to develop such case studies are both quantitative and qualitative, although primarily the latter, with the analytical tools deployed seeking to be reflexive and deconstructive rather than abstractive and conformational. Both Clark $(1998,2007)$ and Yeung $(2003)$ thus highlight the merits of methodological pluralism and triangulation between data collection approaches such as: (a) 'close dialogue' - conversation between researchers and insiders built upon a closeness 
and personal commitment; (b) observation - in situ experiential research that allows economic practices to be studied as they happen; and (c) content analysis of documents - the deconstruction of corporate or governmental reports to reveal examples of economic power's form and effect.

The usefulness of 'new' economic geographical approaches are demonstrated in analyses of how, through a plethora of intra, inter and extra-firm networks of power relations, TNCs drive processes of industrial upgrading, institutional change, market (re)production etc (see Clark et al., 2002; Clark and Wójcik, 2005; Coe et al., 2009; Hess and Coe, 2006; Hughes et al., 2007; Liu and Dicken, 2006; Peck et al., 2005; Wrigley et al., 2005; Yeung, 2009). These analyses have shown that the power relations used by TNCs are spatially heterogeneous because of the way they are embedded by country-to-country variations in, amongst other things, regulatory regimes and market conditions that determine the usefulness, availability of and characteristics of the assets that can be used to construct power relations (thus dealing with component (1) of the analytical approach outlined above). However, despite the advances such studies offer, they do have some shared limitations, common to many other economic geographical studies of power, relating to the second (exercising) and third (responses of contending parties) components of geographical analysis of power. Specifically, existing studies of power need further refining to ensure they conform to the validity and reflexivity principles of the 'new' economic geography paradigm that they draw methodological 
inspiration from. For Yeung (2003), valid data reveals the socio-spatial contingencies that underlie economic activities. Reflexivity means the deployment of an analytical approach that allows researchers to go beyond the immediate and challenge stylized facts by identifying subterranean causes of unevenness in the economy. To ensure validity in studies of power means deploying methodological approaches that generate real time data about the spatiotemporal specificities of the way contending parties strategise, interact through mediating devices, respond to one another's attempts to enforce or resist power, and the results of all of this in terms of the modality of power produced and its impacts. Reflexivity in studies of power requires a systematic mode of analysis in order consider how asset exercising strategies and responses to them seek to generate particular forms of logics and action that undergird power relations (see Table 1). To date, it has been widely noted that empirical analysis that provide such validity and reflexivity are all too rare. As Yeung $(2005,38)$ points out, when deployed to study power in relational economic geography, the methodological approaches adopted in existing studies often led to work which "is relational only in the thematic sense that relations among actors and structures are an important theme in contemporary economic-geographical enquiry. In particular, the causal nature of relationality and power relations are undertheorized and under-specified". Sunley (2009) raises similar concerns. For him "there is a certain irony in that although relational work often call for the analysis of the grounded mechanisms and actual exercise of power, its core concepts, such as value power, and embeddedness, are difficult to operationalize and identify empirically". Illustrating this difficulty, Tokatli $(2007,77)$ argues that existing empirical approaches can be limiting because 
"The nature of the empirical material almost never allows researchers to articulate the learning mechanisms that change power relations...because of an unwillingness or inability of decision makers in forms to describe or articulate to researchers what they learn from others". Particularly significant in relation to the difficulty Tokatli highlights is the preponderance towards post-hoc study of the construction of power through interviews that reflect back on how power was constructed, rather than the use of real time data that actively studies construction in action.

In the rest of the paper I, therefore, explore ways of enriching existing economic geographical approaches to empirically studying power. I do this by considering what can be learned from strategies used elsewhere in the social sciences so as to allow evolution in the way 'new' economic geographical methods are used to study the modalities and whereabouts of power. I.e., I do not suggest reinventing the theoretical or methodological basis for economic geographical study of power. But I do suggest a more nuanced approach to data collection and analysis is needed and can be developed through interdisciplinary gazes towards research on power elsewhere in the social sciences. I make this argument, first, by outlining how comparative approaches and existing methods adopted by economic geographers can be applied in new ways if inspiration is taken from studies of power relations in critical management studies. I then, second, outline how critical discourse analysis techniques - 
already recognised by economic geographers as valuable - can be better put to work if consideration is given to the way they are used in linguistics.

\section{Alternative possibilities: micro-scale ethnography and critical discourse analysis}

This section explores approaches taken to studying power relations in work on identity regulation in management studies and on critical discourse analysis (CDA) in linguistics. Both bodies of work assume that research of power relations will focus on deliberate attempts to construct and/or exercise power in a relatively overt manner with language used to provide insights into the construction and exercising processes. Specifically, what is said and written in different contexts is the main data source analysed. Here, in line with economic geographers' existing understanding of power's basis in both structure and social agency, the way the logic of critical realism (Bhaskar, 1989; Sayer, 2000) has been deployed in work on identity regulation and CDA is considered. This approach, which is based on the principles of 'analytical dualism' (Sayer, 2000), at one level, views language as a medium through which it is possible to study structural influences on power. Language is used to reveal how structural assets such as uneven wealth distribution are exercised, for instance being enrolled to construct threats, inducements etc. At another level, in the 'analytical dualism' perspective language is also interrogated in a Foucauldian sense as a social event and a medium through which the agency of individuals to construct discursive logics which undergird power relations can be revealed. A critical realist perspective on language operates, then, "an analytically dualist epistemology 
which gives primacy to researching relations between agency (process, and events...) and structure and the basis of a realist social ontology" (Fairclough, 2005, 916).

Identity regulation and method (validity) insights

The focus of identity regulation work is on the way power can be used to change the identity of individuals working for firms (for a summary see Alvesson et al., 2008), with identity assumed to shape behaviour. Thus identity regulation has been shown to be used, amongst other things, to ensure a firm's ethical business principles are adhered to by employees (Kornberger and Brown, 2007) or a particular culture of professionalism is displayed in the workplace (Thornborrow, 2009). Taking inspiration from suggestions that "organizations are continuously created and re-created in the acts of communication between organizational members, rather than being independently 'out there'"' (Idema and Wodak, 1999, 7), empirical studies of identity regulation seek to study the nitty-gritty of the construction through social interactions of power relations using micro-scale ethnographic data collection techniques observation and interviewing especially (see Table 2). As Table 2 also reveals, studies are longitudinal, taking place over several months or even years, so as to reveal how the strategies of actors evolve over time as parties interact and respond to one-another's tactics to construct and resist power relations (see also Hodgson, 2005; Vaara et al, 2003). 
Observational data collection in identity regulation studies usually involves, in particular, recording, using video or traditional ethnographic note-taking, interactions between workers and managers - for example in training sessions, formal meetings, or telephone conferences in order to capture snippets of conversation. These conversations reveal the metaphors (Vaara, et al., 2003), stories and myths (Kosmala and Herrbach, 2006) and direct orders (Anderson-Gough, Grey and Robson, 1998) built as part of attempts to construct power. At the same time, the way attempts to become powerful are resisted by contending parties is captured, for example by observing the production of alternative logics (Elsbach and Bhattacharya, 2001) or the use of cynicism or irony as a way of questioning contending parties' claims (Dent, 2003; Fleming and Spicer, 2003; Kosmala and Herrbach, 2006). Finally, follow-up interviews as well as secondary data, such as memos and reports, are then used to explain observations. In particular, those seeking to become powerful are interrogated through interviews in order to tease out the reasons for particular logics being constructed in stories, metaphors etc, whilst contending parties are interrogated to enhance understanding of the choices made about how to respond to others' attempts to dominate, seduce, coerce or gain authority over them.

[Insert Table 2 somewhere here]

The kinds of micro-scale ethnographic approaches taken in work on identity regulation have been used previously by economic geographers to study power relations (for example see 
Clark, 1998; Dunn, 2007; Hughes et al., 2007). But, identity regulation studies provide a number of insights into how to more fully realise the value of the qualitative ethnographic tools of 'new' economic geographical methods. For intra-firm relations (on which see Faulconbridge, 2008; Jones, 2007), and most directly mirroring the approach taken in identity regulation studies, observations of interactions between managers and workers, interviews with parties on both sides of the relationship, and scrutiny of written communications between the parties should be used provide the raw materials for empirical study. Micro-scale ethnographic approaches can also be taken in analysis of inter-firm relations (Hess and Coe, 2006) - for example, a firm's meetings with suppliers or regulators might be attended; suppliers, regulators and the firm's sub-contracting and compliance managers interviewed; and tender documents and responses to regulatory consultations scrutinised. Analysis of extrafirm relations involving governments, (Liu and Dicken, 2006; Weller, 2009) and intergovernmental organisation such as the IMF (Larner, 2000; Swain, 2006) would similarly benefit from observational work. Interviews with the key protagonists, and scrutiny of the archives of minutes from meetings kept by the organisations in question, would then be used not in isolation as is often the case in existing studies but alongside and to help interpret observational data gained from attendance at meetings, workshops, training sessions etc.

At its simplest, the adoption of micro-scale ethnographic data collection strategies would allow description of the various elements of the double contingency of power relations. For instance, 
the use of a particular mediating device and consequently the reach of a power relation can be described. Halliday and Caruthers (2009) reveal the value of such observation-informed description when they document the pivotal role of on-the-ground task forces sent by the IMF in implementing international financial regulation relating to bankruptcy. More subtly, description would provide insights into the way geographical contingencies in asset availability effects the construction of power. Illustrating this, Brown and Humphreys (2006) noted through their observations that reference to place and the particular assets it affords individuals or groups acts as a tool in the construction of power relations. For instance, reference made to the fact that regulation in a place (as an asset) permits the changes in working practices demanded reveals the geographical contingency of power relations at work in any firm. Observations also reveal the role of time/place specificities in asset availability in shaping the reactions of the individuals or groups having power exerted over them. Halford and Leonard (2006) demonstrate this by focussing on the 'baggage'-i.e., institutionally generated subjectivities, beliefs and norms - that individuals bring with them and which shape reactions to power strategies. Micro-scale ethnography unveils the way that 'baggage' is place specific with, for instance, overt reference in discussions to the role of identities, cultures and subjectivities tied to the institutions of particular regions such as Silicon Valley (Benner, 2003) or the City of London (Faulconbridge, 2007; Hall and Appleyard, 2009) being examples of the kinds of assets, unique to a place, observed to be exercised in responses to the exertion of power. 
To summarise, then, the argument put forward here, most fundamentally is that micro-scale studies of the enactment of identity regulation provide some key lessons for economic geographers about how to empirically study power using familiar but often under or imprecisely used data collection tools. The discussion above shows that it is important is to ensure the alignment of research methods more squarely with the questions about the double contingency of power being asked, something which necessitates studying: (a) in real time the social interactions through which available assets are exercised (components (1) and (2) of geographical analyses of power); and (b) responses, as they happen, of contending parties to others' attempts to become powerful and the effects of responses on the modality and effect of power (component (3) of analyses). Micro-scale ethnography is a powerful way of developing such aligned methods, especially if deployed as part of the comparative research that economic geographers often favour - facilitated for example by completing studies of the same firm/union-inter-governmental organisation operating in different places or at different moments in time. To develop such research, 'closer' dialogue than the stand-alone interview completed after the construction of power relations is however needed, with ongoing observation, the building of long-term relationships with research subjects and repeat interviewing providing the tools to understand power as a processual relational construction. This suggests greater use of ethnography by economic geographers is essential (on which see 
Dunn, 2007), as part of a re-evaluation and evolution in the way the methods of 'new' economic geography are deployed.

Micro-scale ethnography does not, however, necessarily solve all of the validity and reflexivity problems plaguing economic geographers' work. In particular, work on identity regulation provides no analytical tools for reflexively 'going beyond the obvious' in data collected. As the reader will have noted, the descriptions above of how micro-scale ethnographic data can be used to reveal insights into the reach and assets used to construct power relations offer little in the way of explanation of why such forms of reach exist or how reach and/or the availability of particular assets is ultimately related to the emergence of particular modalities of power. If the geographies of power are to be fully unpicked, analysis of micro-scale ethnographic data needs to be capable of unpicking the interconnections between the three different components of the double contingency of power relations, for example by showing exactly how assets are exercised in metaphors, stories etc by those seeking to become powerful or respond to the exertion of power by others, the way logics are built using these assets, the reasons for particular strategies being adopted and the overall effect on the modality and impact of power relations. Below I, therefore, suggest that insights from work in linguistics on CDA should also be used alongside insights from work on identity regulation to develop such reflexivity and ability to 'go beyond the obvious', something crucial to further enhancing economic geographical analyses of power. 
Critical discourse analysis and reflexivity in studies of power

Forms of discourse analysis have been used previously by economic geographers (see Kelly, 2001; Larner and Walters, 2000; Wong and Bunnell, 2006) to reveal the way power relations are constructed not only through social interactions but also through non-humans such as official reports and other textual medium that act as mediating devices. To develop this line of work further, it is suggested that a more sophisticated deployment of the analytical framework provided by CDA for interpreting data generated by micro-scale ethnographic studies is needed than has been the case to date." In particular, economic geographers can, I contend, learn from two of the core principles of work on CDA, with these principles forcing analysis to be more reflexive (systematic and critical) when unpicking qualitative research data.

The first principle - analysis of the deliberate production of power - is important because it highlights the value of revealing both obvious but also more subtle, everyday and easy to miss "strategic ways to change the mind of others in one's own interests" (van Dijk, 1993, 254, original emphasis). The second principle of CDA - a focus on the reception of power strategies is important because it draws attention to the way that a power production strategy is not a 
"portable resource" but is instead "contingent on context" (Grant and Hardy, 2003, 8). CDA analyses of reception explore the way production strategies get interpreted and responded to in the social minds of recipients (van Dijk, 1993), the logic of such analysis being built on insights from the work of Bakhtin (1986) and Kristeva (1986) into the dialogicality of all social events. So "a text only makes sense to someone who makes sense of it, someone who is able to infer meaning those meaningful relations" (Fairclough, 1992: 84). Those inferring meaning are said to be influenced by a range of social factors such as age, gender, ethnicity and sexuality but also by cultural variables, institutionalised norms and values and economic and political structures that are all specific to a place and/or time (Bernstein, 1990).

The focus on production and reception in CDA aligns well with the questions about the spatial and temporal double contingency in power relations that economic geographers seek to address. Production corresponds with questions about assets and their exercising, whilst reception corresponds with questions about the significance of the responses of contending parties. To analyse production and reception CDA researchers deploy the tools of normalization not only for making sense of data relating to social interactions - eg, face-toface meetings - but also other forms of text-based linguistic data - eg, the way memos or reports are used to construct logics and power relations. Normalization analysis scrutinises three dimensions of the data gained from observations, interviews and/or texts. Questions are asked about: 
1. Representation of structure - how reference to a perceived social or physical structure of the world is used to promote a particular logic.

2. Description of action - how language is used to suggest a particular action is appropriate or expected.

3. Identification - how a commitment to a particular logic is explicitly made.

Table 3 reveals the questions that are asked of data in order to reveal examples of representation of structure, description of action and identification. By asking the questions outlined in Table 3 about both the strategies of an individual or group seeking to render themselves powerful, and about the strategies of contending parties responding to attempts to exert power over them, the aim is to go beyond what an initial coding of a transcript or document reveals and scrutinise in detail the foundations, be they structural or agencydiscursive, of the social conditions that shape power relations. Specifically, Titscher et al. $(2000,153)$ suggests that the insights that normalization analysis provides enable description (the empirical accounting for), interpretation (theoretical sense-making) and explanation (implication drawing) in studies of power.

For economic geographers, as already suggested above, description involves ensuring the rich data collected through micro-scale ethnography is leveraged to paint a picture of the different components of the double contingency of power relations in any particular context. 
Interpretation involves asking the questions outlined in Table 3 to reveal how the particular modality of power that emerges and its impacts is determined by connections between assets available and used, mediating devices deployed, and the reactions of contending parties. Developing the examples above of the role in the construction of and responses to power relations of place-specific assets such as regulation (Brown and Humphreys, 2006) and cultural and other subjective 'baggage' (Halford and Leonard, 2006), interpretation would reveal, in the language of CDA outlined in Table 3, phenomenon such as the manifest representation using proximate mediating devices (meetings) of geographically-specific structure as an asset in an argument (what regulation permits and what culture renders inappropriate), leading to constuitive logics being put forward by those seeking to become powerful about the kind of change in economic practices that should occur, something responded to by contending parties lexically through promises to implement changes, these promises being made because stories told in negotiations about the changes imposed elsewhere reassured contending parties about the legitimacy and unobtrusive nature of change, and because promises were made by those seeking to become powerful that adaptations to practices would occur to render them more culturally sensitive. Unveiling such dynamics helps to explain why a firm/government/inter-governmental organisation seeking to become powerful develops a particular form of power relation, for instance becoming authoritative because of the legitimacy created for their demands through the logics constructed and because of the particular response of contending parties to the demands, something which in turn helps 
explain the qualitative nature of change (see Table 1 on how modality is related to the nature of change).

Table 4 further outlines how the rich empirical description enabled by micro-scale ethnography, when interpreted using tools of CDA, helps advance economic geographical studies of power. It reveals that the fundamental questions about the modalities and whereabouts of power can be probed from multiple directions to reveal the ongoing timeplace specific work of those seeking to become powerful and responding to the exertion of power over them. As Table 4 also reveals, the explanation component of the tri-partite analytical approach of CDA then allows the linking of description and interpretation to generate findings relevant to generic theoretical-empirical questions about power. Three examples illustrate the kinds of questions that can be addressed through CDA inspired explanation.

[Insert Table 4 somewhere here]

First, explanation would reveal the reasons for individuals and groups generating geographically heterogeneous paces of change in the structure of economies, practices of firms, etc. For example, underlain by recognition that global production networks are inevitably politically contested (Levy, 2008), why two TNCs entering the same country have 
different levels of impacts on economic practices and market structures (on this issue see Durand and Wrigley, 2009), or why the same TNC more quickly drives reform in one place than another (see Christopherson, 2007), are conundrums researchers continue to seek to address. The empirical description and interpretation process outlined above would be useful for revealing how differences in the assets available to a TNC at a particular place or time, diverse decisions about how to exercise the assets available, and variations in the way contending parties react to the TNC's strategies all lead to the development of geographically heterogeneous power relations with workers, suppliers etc, this heterogeneity explaining differences in the political contestations and the pace of change inspired; change being rapid and sustained in some cases (eg, authoritative relations being develop thanks to the placespecific asset availability) but slow and fragile in others (eg, when seduction is relied upon due to different asset availability). When extrapolated outside of the realm of the firm, the same analytical principles also provide the basis for explanations of the causes of other forms of geographical unevenness in the economy - eg, understanding of the reasons for different modalities of power emerging can be used to help explain why the role of the WTO and IMF in neoliberalization has led to some economies adopting capitalist modes of production more quickly (eg, Taiwan) than others (eg China), the insights from such analysis in turn being useful for informing the development of strategies for resisting/slowing neoliberalizaiton. 
Second, explanation also provides a way of unpicking the reasons for institutional change driven by processes of globalization being qualitatively variable across space and leading to the continued geographical unevenness of the economy (on which see Brenner et al., 2010; Clark et al., 2002; Clark and Wójcik, 2005; Coe et al., 2009; Peck et al., 2005; Wrigley et al., 2005; Yeung, 2009). An explanation based on the kind of description and interpretation outlined above would highlight how spatio-temporal contingencies in the various assets available to and the subjectivities, values and priorities of contending parties lead to place-specific variations in regulators, unions, workers and others' responses to attempts to change both the formal rules and informal norms associated with institutions. Such variations result in different kinds of compromises being negotiated in different situated communities (e.g. the unexpected exceptions made by the WTO in relation to free trade in the professions in one country but not another); place-specific negotiated compromises being the basis for the production of economic unevenness and qualitative variegation caused by processes of globalization.

Third, the interpretative tools of CDA have the ability to demonstrate how the spatial reach of power relations is determined by the intersecting influences of the affordances of the available assets, mediating devices used to exercise assets and construct logics/arguments/stories/demands, the types of change in behaviour sought, and the peculiarities of the reactions of contending parties. To unpick such connections, the following questions can be asked of the data generated by micro-scale ethnography: which modalities of 
power are associated with which mediating devices, how does the ability to use the mediating device to construct logics, make demands etc determine this relationship, and how does this relationship influence the spatial reach of different modalities? In what ways does the intra (eg, workers-managers), inter or extra-firm (eg, managers-suppliers practices) nature of interactions between contending parties, the different socio-cultural characteristics of these relations, and the effects of these characteristics on exercising and response strategies determine whether virtual or embodied encounters are deployed, thus determining reach? Does the degree of change in behaviour/practice/governance etc sought or achieved influence choice of or depend on the use of particular proximate or distanciated mediating devices? Answers to these questions can then be used to push forward debates such as those relating to the topological and relational spatiality of governance (Brenner, 1998; Larner, 2000) and the relations and communities that drive change in business practices and institutions (see Amin and Cohendet, 2004; Faulconbridge, 2008; Gertler, 2008); both of these being domains in which power relations are known to be crucial (see Swyngedouw, 1997, and Fox, 2000, respectively) but are often underspecified with data providing few insights into the determinants of reach.

\section{Conclusions}

In opening up debate about how to empirically study the modalities and whereabouts of power, this paper has outlined the value of interdisciplinary gazes for enhancing research 
methods and data analysis techniques. The discussion shows that a rethinking of the use of familiar techniques (close dialogue, observation) alongside the adoption of new analytical approaches (CDA) is needed in economic geography so as to allow the challenges of validity and reflexivity that have hereto limited empirical studies of power to be overcome. Such methodological advances are important because they build on and generate data relevant to the fundamental conceptualisation of power that has been embraced in economic geography with its focus on asset availability, asset exercising, and responses to the exercising of assets; the constituents of what Sayer (2004) refers to as the double contingency of power. Specifically, the methodological approach outlined in this paper provides a way to translate such conceptualisations into concrete data collection and analysis strategies that can address pressing research questions about power and its effects.

The discussion here should not, however, be seen as an attempt to foreclose debates about the type of interdisciplinary gazes needed to advance analyses of power. Rather it should be seen as an attempt to open-up debate about the range of insights that can be gained from multiple sections of the social sciences. There are two potential ways such interdisciplinary gazing could be taken forward. At one level, it would be valuable to consider what can be learned from a wider survey of work on CDA. Here attention is drawn to a number of the core components of CDA techniques, but other components, suited to particular types of analytical context, may also help address certain economic geographical questions. For instance, work on 
intertextuality (see Fairclough and Wodak, 1997), which considers how multiple documents are used to construct robust logics through the cross-referencing of one-another, may be useful for analysing power in policy communities - eg, the way transnational actors such as the World Trade Organization enforce treaties by drawing on principles outlined in a variety of reports and agreements. Work on the role of social, political and fantasmatic logics and the way they are used to stabilise a particular worldview, create visions of the future and promote certain types of action (see Glynos and Howarth 2007) can explain how governments, firms or other organizations promote new models of environmentally or financially sustainable economic regulation and practice, including the role of alternative economies (see Fuller et al., 2010). At another level, the analysis here suggests that economic geographers should also look to other schools in the social sciences to help enhance analyses of power. Disciplines such as anthrpology (eg, political and post colonial anthropologies), development studies (eg, global governance studies) and politics (eg, international relations analysis) have been recognised previously by economic geographers as a source of theoretical inspiration. But they may also be sources of empricial inspiration, providing tools for valid and reflexive analysis which can be honed and adapted to makeup for any lack of spatial or temporal senstivity. There remains, then, a wide array of opportunties to further refine approaches taken in empirical studies of power through the kind of interdisciplinary gazing promoted here. 
There are, of course, scholarly implications of borrowing research methods and analytical tools from elsewhere in the social sciences (on which see Barnes et al., 2007). At one level, questions need to be asked about the practicalities of adopting the kinds of interdisciplinary approaches outlined here. If new methods and analytical tools are adopted, how might the challenges of negotiating access to complete the type of research promoted and developing the skills needed to deploy the methods and analytical devices identified be managed? What implications do the methods used elsewhere in the social sciences (for example in anthropology) have for the timescales of research projects and publication? If economic geographers' methods do become more diverse, what are the implications of this for the type of training needed by the next generation of scholars? At another level, more fundamental questions also need to be asked about how diverse economic geographical research methods should be. Do economic geographers need their own unique tools or is interdisciplinary borrowing sufficient to meet research needs? How can borrowing contribute to ongoing geographical research agendas, rather than create new agendas before existing questions have been fully addressed? Does economic geography need to develop research tools that can be lent to other social science disciplines? Peck (2005) has considered such issues relating to theoretical borrowing, making it clear that there are both risks and opportunities for economic geographers. But, in relation to methodological borrowing there has been less substantive debate. This is not the place to try to settle such debates. Nonetheless, the current paper does remind economic geographers of the importance of developing what Barnes et al. (2007) refer to as a research practice that is aligned with the politics and aims of economic geographical 
study. And as Sayer (2004) indicates, theory can only go so far in developing understanding of important economic geographical issues such as power and, therefore, in answering the questions raised by the interdisciplinary gazing promoted here it would seem prescient to be pragmatic and realistic, but also critical of the orthodoxy in terms of empirical research strategies. Pragmatism and realism is needed, firstly, to recognise the limitations of the kinds of rich ethnographic studies outlined here. For instance, accessing government departments to complete ethnography, whilst not impossible, is likely to be time consuming and fickle in terms of success. Consequently multi-methods approaches that ensure micro-scale ethnography is not the only data collection tool deployed would seem sensible and might mitigate some of the costs of such an approach. Illustrating this, as noted above, deploying the various CDA techniques designed specifically for documents alongside ethnography may be valuable. Pragmatism is also needed, secondly, because economic geographers may need to consider the merits of interdisciplinary team working. Collaborations with scholars from management, politics or linguistics who are familiar with the challenges of deploying micro-scale ethnography and CDA techniques seem likely to be a fruitful strategy for further advancing empirical endeavours, so long as room is created in such teams for an explicit spatio-temporal focus in analyses. But, the need for such a pragmatic and realistic approach should not be used as an excuse for not casting a critical eye over the research methods used by economic geographers. The development of empirical research strategies suited to the social phenomena being studied and evolving theoretical understanding of these phenomena is crucial but inevitably involves rethinking how empirical economic geographical research is 
approached, something which, as demonstrated in this paper, is challenging but potentially rewarding if followed through.

\section{Acknowledgements}

I am grateful for the generous comments of three anonymous Reviewers that helped sharpen the argument of the paper considerably. The ideas presented in this paper were developed as part of the project 'Professional education, global professional service firms and the cultures of professional work in Europe'. This project was funded by the Economic \& Social Research Council (grant RES-000-22-2957). Elspeth Oppermann introduced me to much of the work on CDA discussed in the paper and made me cognisant of the power of the approach's analytical tools.

\section{References}

Allen, J. 2003: Lost Geographies of power. Oxford: Blackwell.

Allen, J. 2004: The whereabouts of power: politics, government and space. Geografiska Annaler B: Human Geography 86B, 19-32.

Alvesson, M., Ashcraft, K. and Thomas, R. 2008: Identity matters: reflections on the construction of identity scholarship in organization studies. Organization 15, 5-28.

Amin, A. and Cohendet, P. 2004: Architectures of knowledge: Firms capabilities and communities. Oxford: Oxford University Press. 
Amin, A. and Thrift, N. 2000: What kind of economic theory for what kind of economic geography? . Antipode 32, 4-9.

Anderson-Gough, F., Grey, C. and Robson, K. 1998: Making up accountants: the professional and organizational socialization of trainee chartered accountants. Aldershot: Ashgate/ICAEW.

Arendt, H. 1958: The human condition. Chicago: University of Chicago Press.

Bakhtin, M. 1989: Speech genres and other late essays, ed. C. Emerson and M Holquist, tranlsated by V.W McGee. Austin: University of Texas Press.

Barnes, T.J., Peck, J., Sheppard, E. and Tickell, A. 2007: Methods matter: Transformations in economic geography. In Tickell, A., Sheppard, E., Peck, J. and Barnes, T.J., editors, Politics and practice in economic geography, London: Sage, 1-24.

Bathelt, H. and Glücker, J. 2005: Resources in economic geography: from substantive concepts towards a relational perspective. Environment and Planning A 37, 1545-1563.

Beech, N. 2008: On the nature of dialogic identity work. Organization 15, 51-74.

Benner, C. 2003: Learning communities in a learning region: the soft infrastructure of cross-firm learning networks in Silicon Valley. Environment and Planning A 35, 1809-1830.

Bernstein, B. 1990: The structuring of pedagogic discourse. London: Routledge.

Bhaskar, R. 1989: Reclaiming reality: A critical introduction to contemporary philosophy. London: Verso.

Brenner, N. 1998: Between fixity and motion: accumulation, territorial organization and the historical geography of spatial scales. Environment and Planning D 16, 459-482.

Brenner, N., Peck, J. and Theodore, N. 2010: Variegated neoliberalization: geographies, modalities, pathways. Global Networks 10, 182-222.

Brown, A., Humphreys, M., Down, C. and Campus, J. 2006: Organizational identity and place: a discursive exploration of hegemony and resistance. Journal of management studies 43, 231-257.

Brown, A.D., Kornberger, M., Clegg, S.R. and Carter, C. 2010: 'Invisible walls' and 'silent hierarchies': A case study of power relations in an architecture firm. Human Relations 63, 525-549.

Christopherson, S. 2007: Barriers to 'US style' lean retailing: the case of Wal-Mart's failure in Germany. Journal of Economic Geography 7, 451-469.

Clark, G. 1998: Stylized facts and close dialogue: methodology in economic geography. Annals of the Association of American Geographers 88, 73-87. 
Clark, G.L. 2007: Beyond close dialogue: Economic geography as if it matters. In Tickell, A., Sheppard, E., Peck, J. and Barnes, T.J., editors, Politics and practice in economic geography, London: Sage, 187-198.

Clark, G.L., Mansfield, D. and Tickell, A. 2002: Global finance and the German model: german corporations, market incentives, and the management of employer-sponsored pension instituions. Transactions of the Instittue of British Geographers NS 27, 91-110.

Clark, G.L. and Wojcik, D. 2005: Path dependence and financial markets: the economic geography of the German model, 1997-2003. Environment and Planning A 37, 1769-1791.

Clegg, S.R. 1989: Frameworks of power. London: Sage.

Coe, N., Hess, M., Yeung, H.W.-C., Dicken, P. and Henderson, J. 2004: 'Globalizing' regional development: a global production networks perspective. Transactions of the Institue of British Geographers NS 29, 468-484.

Coe, N.M., Johns, J. and Ward, K. 2009: Agents of casualization? The temporary staffing industry and labour market restructuring in Australia. Journal of Economic Geography 9, 55 - 84.

Cumbers, A., MacKinnon, D. and McMaster, R. 2003: Institutions, power and space: assessing the limits to institutionalism in economic geography. European urban and regional studies 10, 325.

Cumbers, A., Nativel, C. and Routledge, P. 2008: Labour agency and union positionalities in global production networks. Journal of Economic Geography 8, 369-387.

Deleuze, G. and Guttari, F. 1988: A thousand plateaus: capitalism and schizophrenia. London: Athlone Press.

Dent, M. 2003: Managing doctors and saving a hospital: Irony, rhetoric and actor networks. Organization 10, 107-127.

Dunn, E. 2007: Of pufferfish and ethnography: plumbing new depths in economic geography. In Tickell, A., Sheppard, E., Peck, J. and Barnes, T.J., editors, Practice and Politics in Economic Geography. , Thousand Oaks: Sage, 82-93.

Durand, C. and Wrigley, N. 2009: Institutional and economic determinants of transnational retailer expansion and performance: a comparative analysis of Wal-Mart and Carrefour. Environment and Planning A 41, 1534-1555.

Elsbach, K. and Bhattacharya, C. 2001: Defining who you are by what you're not: Organizational disidentification and the National Rifle Association. Organization Science, 393-413.

Fairclough, N. 1992: Discourse and social change. Cambridge: Polity Press. 
Fairclough, N. 2005: Peripheral vision. Discourse Analysis in Organization Studies: The Case for Critical Realism. Organization Studies 26, 915-939.

Fairclough, N. and Wodak, R. 1997: Critical discourse analysis. In van Dijk, T., editor, Discourses as social interaction, London: Sage.

Faulconbridge, J.R. 2007: Exploring the role of professional associations in collective learning in London and New Yorkłs advertising and law professional service firm clusters. Environment and Planning $A$ 39, 965-984.

Faulconbridge, J.R. 2008: Negotiating cultures of work in transnational law firms. Journal of Economic Geography 8, 497-517.

Faulconbridge, J.R. and Hall, S. 2009: Organisational geographies of power: Introduction to special issue. Geoforum 40, 785-789.

Faulconbridge, J.R., Beaverstock, J.V., Hall, S. and Hewitson, A. 2009: The 'war for talent': the gatekeeper role of executive search firms in elite labour markets. Geoforum.

Fleming, P. and Spicer, A. 2003: Working at a cynical distance: Implications for power, subjectivity and resistance. Organization 10, 157-179.

Foucault, M. 1980: Power/knowledge: Selected interviews and other writings, 1972-1977. Translated by C. Gordon, L. Marshall, J. Mephram, \& K. Soper. New York: Pan-theon.

Fuller, D., Jonas, A.E.G. and Lee, R. 2010: Interrogating Alterity: Alternative Economic and Political Spaces. Aldershot: Ashgate.

Gertler, M. 2008: Buzz without being there? Communities of practice in context. In Amin, A. and Roberts, J., editors, Community, economic creativity and organization, Oxford: Oxford University Press, 203-226.

Giddens, A. 1977: Studies in Social and Political Theory. London: Hutchinson.

Glynos, J. and Howarth, D. 2007: Logics of critical explanation in social and political theory. . London \& New York: Routledge.

Grant, D. and Hardy, C. 2004: Introduction: Struggles with organizational discourse. Organization Studies 25, 5-13.

Halford, S. and Leonard, P. 2006: Place, space and time: contextualizing workplace subjectivities. Organization Studies 27, 657 - 676. 
Hall, S. and Appleyard, L. 2009: City of London City of learning? Placing business education within the geographies of finance. Journal of Economic Geography 9, 597.

Halliday, T.C. and Carruthers, B.G. 2009: Bankrupt: global lawmaking and systemic financial crisis: Stanford Univ Pr.

Hess, M. 2004: Spatial\ relationships? Towards a reconceptualization of embeddedness. Progress in Human Geography 28, 165-186.

Hess, M. and Coe, N. 2006: Making connections: global production networks, standards, and embeddedness in the mobile-telecommunications industry. Environment and Planning A 38, 12051227.

Hodgson, D. 2005: 'Putting on a Professional Performance': Performativity, Subversion and Project Management. Organization 12, 51 - 68.

Hughes, A., Buttle, M. and Wrigley, N. 2007: Organisational geographies of corporate responsibility: a UK-US comparison of retailers' ethical trading initiatives. Journal of Economic Geography 7, 491 513

ledema, R. and Wodak, R. 1999: Introduction: organizational discourses and practices. Discourse \& Society $10,5$.

Johns, J. 2006: Video games production networks: value capture, power relations and embeddedness. Journal of Economic Geography 6, 151-180.

Jones, A. 2007: More than Amanaging across borders? $\times$ the complex role of face-to-face interaction in globalizing law firms Journal of Economic Geography 7, 223-246.

Jones, A. 2008: Beyond embeddedness: economic practices and the invisible dimensions of transnational business activity. Progress in Human Geography 32, 71-88.

Jones, A. and Search, P. 2009: Proximity and power within investment relationships: The case of the UK private equity industry. Geoforum 40, 809-819.

Kelly, P.F. 2001: Metaphors of meltdown: political representations of economic space in the Asia financial crisis. Environment and Planning D: Society and Space 19, 719-742.

Kornberger, M. and Brown, A.D. 2007: Ethics' as a discursive resource for identity work. Human Relations 60, 497.

Kosmala, K. and Herrbach, O. 2006: The ambivalence of professional identity: On cynicism and jouissance in audit firms. Human Relations 59, 1393-1428. 
Kristeva, J. 1986: The system and the speaking subject. In Moi, T., editor, The Kristeva reader, Oxford: Basil Blackwell, 24-33.

Labov, W. and Fanshel, D. 1977: Therepeutic discourse: psychotherapy as conversation. New York: Academic Press.

Larner, W. 2000: Neo-liberalism: Policy, ideology, governmentality. Studies in political economy 63, 5-25.

Larner, W. and Walters, W. 2000: Privatisation, governance and identity: the United Kingdom and New Zealand compared. Policy \& Politics 28, 361-377.

Levy, D.L. 2008: Political contestation in global production networks. The Academy of Management Review 33, 943-963.

Liu, W. and Dicken, P. 2006: Transnational corporations and 'obligated embeddedness': foreign direct investment in China's automobile industry. Environment and Planning A 38, 1229-1247.

Mann, M. 1986: The sources of social power, Volume I: A history of power from the beginning to $A D$ 1760 Cambridge: Cambridge University Press.

Mann, M. 1993: The sources of social power, Volume I: The rise of classes and the nation state, 1760 1914. Cambridge: Cambridge University Press.

Massey, D. 1999: Space of politics. In Massey, D., Allen, J. and Sarre, P., editors, Human geography today, Cambridge: Polity Press, 279-294.

Massey, D. 2007: World City. Cambridge: Polity.

Parsons, T. 1963: On the concept of political power. Proceedings of the American Philosophical Society $107,232-262$.

Peck, J. 2005: Economic sociologies in space. Economic Geography 81, 129-174.

Peck, J., Theodore, N.I.K. and Ward, K. 2005: Constructing markets for temporary labour: employment liberalization and the internationalization of the staffing industry. Global Networks 5, 3-26.

Potter, J. and Wetherell, M. 1987: Discourse and social psychology: beyond attitudes and behaviour. London: Sage.

Putnam, L.L. 2004: Dialectical tensions and rhetorical tropes in negotiations. Organization Studies 25, 35-53.

Rose, N. and Miller, P. 1992: Political power beyond the state: problematics of government. British Journal of Sociology 43, 173-205. 
Routledge, P. 2003: Convergence space: process geographies of grassroots globalization networks. Transactions of the Institute of British Geographers 28, 333-349.

Sayer, A. 2000: Realism and social science. London: Sage.

Sayer, A. 2004: Seeking the geographies of power. Economy and Society 33, 255-270.

Sharp, J.P., Routledge, P., Philo, C. and Paddison, R. 2000: Entanglements of power: geographies of domination/resistance. In Sharp, J.P., Routledge, P., Philo, C. and Paddison, R., editors, Entanglements of power: geographies of domination/resistance. New York: Routledge, 1-42.

Sinclair, J. and Coulthard, M. 1975: Towards an analysis of discourse: The English used by teachers and pupils. Oxford: Oxford University Press.

Sunley, P. 2009: Relational economic geography: a partial understanding or a new paradigm? Economic Geography 84, 1-26.

Sveningsson, S. and Alvesson, M. 2003: Managing managerial identities: Organizational fragmentation, discourse and identity struggle. Human Relations 56, 1163.

Swain, A. 2006: Soft capitalism and a hard industry: virtualism, the'transition industry'and the restructuring of the Ukrainian coal industry. Transactions of the Institute of British Geographers 31, 208-223.

Swyngedouw, E. 1997: Neither global nor local: AGlocalization× and the politics of scale. . In Cox, K., editor, Spaces of Globalisation, New York: Guildford, 137-166.

Thornborrow, T. and Brown, A.D. 2009: Being Regimented': Aspiration, Discipline and Identity Work in the British Parachute Regiment. Organization Studies 30, 355 - 376.

Thrift, N. and Olds, K. 1996: Refiguring the economic in economic geography. Progress in Human Geography 20, 311-337.

Tickell, A., Sheppard, E., Peck, J. and Barnes, T.J. 2007: Politics And Practice in Economic Geography: Sage Publications.

Titscher, S., Meyer, M., Wodak, R. and Vetter, E. 2000: Methods of text and discourse analysis. London: Sage.

Tokatli, N. 2007: Asymmetrical power relations and upgrading among suppliers of global clothign brands: Hugo boss in Turkey. Journal of Economic Geography 7, 67-92.

Vaara, E., Tienari, J. and Santti, R. 2003: The international match: Metaphors as vehicles of social identity-building in cross-border mergers. Human Relations 56, 419. 
Van Dijk, T.A. 1993: Principles of critical discourse analysis. Discourse \& Society 4, 249-283.

Weber 1979: Economy and Society, Volumes 1 and 2. New York: Bedminster Press.

Weller, S.A. 2009: Shifting spatialities of power: The case of Australasian aviation. Geoforum 40, 790799.

Wenger, E. 1998: Communities of practice: learning meaning and identity. Cambridge: Cambridge University Press.

Wodak, R. 1989: Language, power and ideology. Amsterdam: Benjamins.

Wong, K.W. and Bunnel, T. 2006: 'New economy' discourse and spaces in Singapore: a cast study of one-north. Environment and Planning A 38, 69-83.

Wrigley, N., Coe, N. and Currah, A. 2005: Globalizing retail: conceptualizing the distribtuion-based transnational corporation (TNC). Progress in Human Geography 29, 437-457.

Yeung, H.W.-C. 2003: Practising new economic geographies. Annals of the Association of American Geographers 93, 442-462.

Yeung, H.W.-C. 2005: Rethinking relational economic geography. Transactions of the Instittue of British Geographers NS 30, 37-51.

Yeung, H.W. 2009: Situating regional development in the competitive dynamics of global production networks: an East Asian perspective. Regional Studies 43, 325-351.

\footnotetext{
'As such, past debates (eg, Amin and Thrift, 2000; Peck, 2005) about the value of economic geographers' engagement with other social science disciplines are recognised and the claim is made that engagement can allow the development of unique geographical approaches to empirically studying the spatio-temporal contingencies of power, allowing contributions to be made to wider-social science theory. This issue and the challenges it poses is returned to again in the Conclusions to the paper.
} 
ii Here I focus on the development of a series of analytical tools in one school of thought on CDA, primarily associated with the work of Norman Fairclough (1992; 2005). I focus on this school of work because of its critical realist perspective on the role of language as an analytical tool, the value of which was outlined above. Other approaches to critical discourse analysis include the work of Sinclair and Coulthard (1975), Labov and Fanshel (1977), Potter and Wetherall (1987) and Wodak (1989). All of these approaches, like that approach of Fairclough, are influenced by Focauldian analyses of power but are based on different philosophical backgrounds and, as a result, ask related but subtly different questions about the production and reception of power. 